To cite this article: Dal A, Dönertaş ŞN. Çocuklarda akut periodontal hastalıkların teşhis ve tedavisi. Turk J Clin Lab 2020; 1: 68-74.

\title{
Çocuklarda akut periodontal hastalıkların teşhis ve tedavisi
}

\section{Diagnosis and treatment of acute periodontal diseases in children}

\author{
Aycan DAL ${ }^{1 *}$, Şafak Necati DÖNERTAŞ² \\ ${ }^{1}$ Gazi Üniversitesi Diş Hekimliği Fakültesi Pedodonti Anabilim Dalı, Ankara/TÜRKiYE \\ ${ }^{2}$ Gazi Üniversitesi Diş Hekimliği Fakültesi Periodontoloji Anabilim Dalı, Ankara/TÜRKiYE
}

Öz

Periodontal hastalıklar ve diş çürükleri oral kavitede karşılaştığımız iki ana hastalıktır. Bu hastalıklar her yaştan bireylerde görülebildiği gibi diş kayıplarının da temel iki nedeni olarak kabul edilir. Pedodonti kliniğine dişetleri ile ilgiliakut şikayetlerle gelen pek çok hastayla karşılaşılmaktadır. Karşılaşılan bu akut problemlerle ilgili bilgi sahibi olmak, klinik durumu tanımlayabilmek ve hastaya doğru medikal veya cerrahi tedaviyi uygulamak büyük önem taşımaktadır. Bu makale çocuk ve genç hastalarda sıklıkla karşılaşılan akut periodontal hastalıkların teşhis ve tedavilerini içeren klinik yaklaşımlara dikkat çekmektedir.

Anahtar kelimeler: akut; periodontal hastalıklar; teşhis; tedavi

\section{Abstract}

Periodontal diseases and dental caries are the two main diseases we encounter in the oral cavity. These diseases can be seen in individuals of all ages and are considered as the two main causes of tooth loss. There are many patients who come to the pediatric clinic with acute complaints in the gums. It is of great importance to have knowledge about these acute problems, to define the clinical situation and to apply medical or surgical treatment to the patient. This article draws attention to clinical approaches that include the diagnosis and treatment of acute periodontal diseases, which are frequently encountered in children and young patients.

Keywords: acute; periodontal diseases; diagnosis; treatment

Sorumlu yazar*: Aycan Dal, Gazi Üniversitesi Diş Hekimliği Fakültesi Pedodonti Anabilim Dalı, Ankara/TÜRKiYE E-posta: aycandal@outlook.com

ORCID: 0000-0002-5876-4586

Gönderim: 28.06.2019 Kabul: 29.07.2019

Doi: $10.18663 /$ tjcl.584171 


\section{Giriş}

Akut periodontal hastalıklar her yaştan bireylerde görülmekle beraber çocuklarda sıklıkla karşımıza çıkan bir durumdur. Tedavisinde doğru tanı ve teşhis önemli yer tutmaktadır.

\section{Primer Herpetik Gingivostomatit}

Primer herpetik gingivostomatit, Herpes Simpleks Virüs Tip 1 tarafından oral kavitede infeksiyona neden olan bir hastalıktır. Genellikle 6 yaşından küçük çocuklar ve infantlarda görülür fakat adölesanlarda ve yetişkinlerde de görülebilir. Çoğu vakada hastalığın primer infeksiyonu asemptomatiktir [1].

Primer herpetik gingivostomatitte virüs, nöral gangliyonlarda latent olarak kalır. Dünya popülasyonunun yaklaşık olarak 1/3 'ünde sekonder form görülür. Bu sekonder form herpes labialis, herpetik stomatitis, herpes genital, oküler herpes ve herpetik ensefaliti de içerir. Sekonder herpetik stomatit; damakta, gingivada veya mukozada dental tedavi esnasında meydana gelen travmalar veya latent virüsün içinde bulunduğu gangliyonun inerve ettiği bölgenin stimülasyonu sonucu meydana gelebilir. Karakteristik veziküller tanı için önemlidir [1].

Primer herpetik gingivostomatitte oral mukoza diffüz, eritematöz, parlak tutulumlu bir gingiva ve çeşitli derecelerde ödemli ve kanamalı görünümdedir. Başlangıç aşaması boyunca gingivada, labial ve bukkal mukozada, yumuşak damakta, farinkste, sublingual mukozada ve dilde oluşan farklı boyutlardaki gri veziküllerle karakterizedir. Yaklaşık 24 saat sonra veziküller rüptüre olur ve ağrılı küçük ülserler, kırmızı marjinler ve sarımtrak veya gri-beyaz santral kısımlı alanlar meydana gelir. Bu bulgular birbirinden ayrı geniş alanlar şeklinde veya birleşmiş kümecikler şeklinde görülebilir [1].

Herpes simpleks virüsle primer infeksiyon sonrası akut herpetik gingivostomatit meydana gelir ve oral infeksiyon sistemik semptomlarla beraber görülür. 7-10 gün boyunca devam eder ve skar bırakmadan iyileşir [2]. Amir ve diğerleri [3]'nin yaptığı çift kör, randomize, plasebo kontrollü çalışmada $15 \mathrm{mg} / \mathrm{kg}$ asiklovir süspansiyonu günde 5 kez, 7 gün boyunca antiviral terapi olarak uygulanmıştır ve semptomların azaldığı görülmüştür.

Eğer primer herpetik gingivostomatit 3 gün içinde tanımlanabilirse asiklovir süspansiyonu reçete edilmelidir $=15 \mathrm{mg} / \mathrm{kg}$, günde 5 kez, 7 gün boyunca. Eğer diagnoz 3 günün sonunda immün sistemi düşmüş bir hastaya konuyorsa, asiklovir tedavisi limitli değerlere indirgenmelidir. 3 gün sonra tanı konmuş hastalar da dahil olmak üzere tüm hastalara palyatif tedavi ve plak ve yiyeceklerden arta kalan debrislerin uzaklaştırılması işlemleri uygulanmalıdır. Ateşi ve ağrıyı azaltması için NSAi ilaç (örn; ibuprofen) sistemik olarak verilebilir. Hastalar ayrıca beslenme öncesinde besin takviyesi ve topikal anestezikleri (örn; visköz lidokain) kullanabilirler. Özellikle primer herpetik gingivostomatitin erken safhalarında periodontal tedavi, akut semptomlar geçene kadar ertelenmelidir [2].

\section{Akut Nekrotizan Ülseratif Gingivitis}

Akut nekrotizan ülseratif gingivitis (ANUG), konak yanıtında bozulma sonucu gingivada oluşan mikrobiyal bir hastalıktır. Bu hastalık nekroz ve gingival dokuda soyulma ile karakterizedir. ANUG genellikle tedaviye gerek duyulmadan azalan bir şiddetle geçirilir. Subakut form denilen bu formda hafif klinik semptomlar gözlenir. Bu semptomlar tek bir diş, bir grup diş veya tüm ağızla ilişkili olabilir [1].

Karakteristik lezyonları, interdental papil kretinde delikli krater tarzındaki depresyon alanları şeklindedir. Çoğunlukla marjinal gingiva etkilenir. Yapışık dişeti ve oral mukoza daha az oranda etkilenmiştir. Dişetindeki krater tarzı lezyonların yüzeyi gri pseudomembranlarla çevrelenmiştir ve bu pseudomembranlar belirgin bir lineer eritemle geri kalan gingival mukozadan ayrılır. Bazı vakalarda lezyonlar, pseudomembran yüzeyinden soyulur ve ekspoze olan gingiva kırmızı, parlak, hemorajik bir şekilde açığa çıkar. Bu karakteristik lezyonlar gingivayı ve altındaki periodontal dokuları şiddetli bir harabiyete uğratır. Spontan dişeti kanaması veya hafif stimülasyonla meydana gelen belirgin kanama da karakteristik klinik bulgulardandır. Diğer bulgular ise sıklıkla kötü ağız kokusu ve artmış salivasyondur [1].

Plaut ve Vincent 1890'lı yıllarda bu hastalığın fusifom-spiroket özelliğini keşfetmişlerdir. Hastalığın tanımına dair yaptığı katkılardan dolayı ANUG, Vincent enfeksiyonu olarak bilinmekteydi [4].

İmmün sistem fonksiyonu değişiklikleri ANUG'ta predispozan faktördür. Dennison ve diğerleri [5] AIDS hastası olanlarda daha yüksek ANUG insidansı olduğunu bildirmiştir.

Barnes ve diğerlerinin [7] yaptığı çalışma sonucunda ağızda en çok etkilenen alanın mandibulanın ön tarafı, en az etkilenen alanın ise molarlar bölgesi olduğu görülmüştür. Ayrıca ANUG'un genç erişkinlerde görülen bir rahatsızlık olduğu, kötü oral hijyen ve diş taşının hastalığın oluşumunda ve artışında etkili olduğu belirlenmiştir.

\section{ANUG tedavisinde:}

1. seans: Illk seansta tedavi akut alanlarla sınırlandırılır. Pamuk rulolarla izole edilip kurutulan akut ve ağrılı bölgelere topikal anestezik uygulanır, 2-3 dakika sonra bu bölgeler nemlendirilmiş bir pamuk peletle nazikçe silinir, pseudomembranlar ve non-atake yüzey debrisleri uzaklaştırılır. Kanama çok fazla olabilir. Her bir pamuk pelet küçük bir alanda kullanılıp atılır. Bu alanlar ılık suyla temizlendikten sonra yüzeyel diş taşları alınır. Ultrasonik temizleyiciler bu iş için kullanışlı aletlerdir. Subgingival temizlik ve küretaj bu seansta kontrendikedir [2]. 
Orta veya şiddetli ANUG'lu hastalarda ve lokal lenfodenopati veya sistemik bir semptomu olanlarda antibiyotik rejimi: Amoksisilin 500mg oral yoldan her 6 saatte bir (4x1), 10 günlük kullanım şeklindedir. Amoksisilin duyarlı hastalarda: Eritromsin 500mg 6 saatte bir veya Metronidazol 500mg günde 2 kez, 7 gün boyunca kullanılır. Sistemik komplikasyonları olmayan ANUG hastalarına antibiyotik önerilmemelidir. Şiddetli ağrısı varsa ağrı kesiciler verilebilir. Hasta, ağrısı geçtiğinde tedavinin tamamlanmış olmadığı konusunda uyarılmalı ve 1-2 gün içerisinde tekrar gelmesi söylenmelidir.

2. seans: Hastanın semptomlarında iyileşme gözlenir. Akut şikayetler azalmış veya tamamen kaybolmuştur. Gingival marjin hala hiperemik olabilir ancak pseudomembranlar kaybolmuştur. Mevcut diş taşlarının tamamı mümkünse nazikçe temizlenip detartraj işlemi bitirilir. Hastaya ilk seanstaki öneriler tekrarlanır. 1-2 gün sonrası için tekrar randevu verilir [2].

3. seans : Genellikle hastada semptom kalmamıştır. İlgili alan hala eritemli, dişeti dokunmaya hassas olabilir. Daha derin diş taşı temizliği, kök düzeltmesi, polisaj yapılabilir. Taşkın dolgu varsa düzeltilir. Ağız hijyeni önerileri tekrarlanır. Hastaya yeni yumuşak bir fırça önerilir. Hidrojen peroksitle ağız çalkalamasına devam edilmez ancak klorheksidinle çalkalama 2-3 hafta daha sürdürülebilir. 2-3 hafta sonrası için tekrar randevu verilir [2].

\section{Rekürrent Aftöz Stomatit}

Rekürrent aftöz stomatit (RAS) lezyonları çapı 0,5 ile $1 \mathrm{~cm}$ arasında değişen, yuvarlak veya ovoid sığ ülserlerdir. Gri sarımsı bir merkezi alan, eritemli bir halo ile çevrelenmiş, daha büyük 1 ile $3 \mathrm{~cm}$ çapında oval veya düzensiz şekilli ülserler olarak da görülebilirler. Küçük lezyonlar yara izi olmaksızın 7-10 günde iyileşirken, büyük lezyonlar haftalarca devam eder ve skarla iyileşir. Etiyolojisi tam olarak bilinmemektedir. Behçet hastalığı ve HIV enfeksiyonu olan çocuklarda RAS lezyonları sıklıkla bulunur [8].

RAS'ın 3 temel klinik türü vardır.

\section{Minör Aftöz Ülserler (Mikulicz Ülseri)}

Çoğunlukla 10-40 yaş grubunda görülür ve çoğunlukla minimal semptomlara neden olur. Çapları 2-4 mm'den küçük yuvarlak veya ovoid ülserlerdir. Ülser zemini başlangıçta sarımtıraktır ancak iyileşme ve epitelleşme ilerledikçe grimsi bir renk alır. Esasen dudaklar, yanaklar, ağız tabanı, dilin sulkusu veya ventrumun keratinsiz mobil mukozasında bulunurlar. Damağın keratinleşmiş mukozasında veya dilin dorsumunda nadiren bulunurlar ve yalnızca birkaç ülser grup halinde (1-6 arası) görülürler. 7-10 gün arasında düzelirler. 1-4 aylık aralıklarla tekrarlarlar [8].

\section{Majör Aftöz Ülserler (Sutton'un Ülseri)}

Daha uzun süreli, daha sık tekrarlayan, daha ağrılı ülserlerdir. Yaklaşık $1 \mathrm{~cm}$ çapındadırlar ancak daha da büyük olabilirler. Dil dorsumu ya da damağın keratinleşmiş kısmı da dahil olmak üzere oral mukozanın herhangi bir bölgesinde bulunabilirler. Bir defada yalnızca birkaç ülser (1-6 arası) grup halinde bulunur ve yavaş yavaş 10 ile 40 gün arasında iyileşirler. Çok fazla tekrarladıklarında skar ile iyileşebilirler [8].

\section{Herpetiform Ülserler}

Çoğunlukla yaşlılarda ve kadınlarda görülür. Vezikülasyon ile başlayıp oral mukozada hızla yayılan ülserlere dönüşürler. Büyüklükleri giderek artar ve birleşirler. Aşırı derecede ağrılıdırlar. 10 gün veya daha uzun sürede iyileşirler [9].

Klorheksidin, topikal kortikosteroidler, topikal tetrasiklin, immünoregülatörler, TNF inhibitörleri, sistemik çinko sülfat, MAO inhibitörleri, sodyum kromoglikat oral ülserlerin tedavisi için kullanılmıştır. Ne yazık ki RAS için özel bir tedavi mevcut değildir. Öte yandan mevcut tedaviler RAS belirtilerini azaltabilir ancak RAS'ı tamamen tedavi edemez veya ülserlerin nüks etmesini önleyemez [10].

Volkav ve diğerlerinin [11] 2009'da yaptığı randomize çift kör, plasebo kontrollü bir çalışmada basit, ucuz ve düşük riskli olan vitamin B12 tedavisi, serum vitamin B12 seviyesine bakılmaksızın RAS'dan muzdarip hastalarda etkili olmuştur.

\section{Akut Streptokokal Gingivitis}

Akut streptokokal gingivitis oral mukozanın akut bir inflamasyonudur. Hem çocuklarda hem de yetişkinlerde görülebilir. Genel direncin düşük olduğu durumlarda ortaya çıkar. Lezyonların başlama alanı genellikle dişeti kenarı ve komşu dişeti papilidir. Akut streptokokal gingivitisin en önemli klinik özelliği dişeti kenarında ateş kırmızısı bir rengin olmasıdır. Bakteriyel smear çoğunlukla Streptokokus Viridans varlığını gösterir fakat farklı çalışmalarda A grubu beta $\beta$ - hemolitik streptokokların da bulunduğu rapor edilmiştir [1].

Akut streptokokal gingivitis şişkin, parlak kırmızı, kolay kanayan bir dişeti, ağrı, ateş, rahatsızlık hissi ve submandibular lenfadenit ile karakterizedir [12,13]. Apse formasyonları da görülebilir. Mikrobiyolojik örnekleme ile hasta tanısı kesinleştirilir [14]. Streptokokal gingivitisin tedavi edilmesi oldukça önemlidir. Çünkü sepsis, menenjit, perikardit, romatizmal ateş ve pnömoni gibi sistemik sekonder infeksiyonlara sebep olma riski yüksektir $[15,16]$. Antimikrobiyal olarak özellikle penisilin kullanılmaktadır $[12,13]$. Sistemik antibiyotik kullanımı septisemi, menenjit, perikardit, romatizmal ateş ve pnömoni gibi sekonder infeksiyonları önlemek için önerilmektedir $[15,16]$.

Tedavi semptomatiktir. Ağız hijyeninin düzeltilmelidir. İlk aşamada supragingival temizlik ve klorheksidin irigasyonu yapılmalı, gingival inflamasyondan sorumlu olabilecek tüm lokal iritanlar uzaklaştırılmalıdır. Hastaya antibiyotik (amoksisilin ve 
potasyum klavulanat 1000mg, 2x1, 10 gün), analjezik (naproksen $550 \mathrm{mg}, 2 \times 1$, 5 gün) reçete edilmeli ve hasta 2 hafta boyunca \%0,12'lik klorheksidinle ağız çalkalama yapmalıdır. Hastaya oral hijyen motivasyonu yapılmalı ve yumuşak kıllı fırça önerilmelidir. 2 hafta sona gingivanın etkilenen bölgesinde daha az ağrı ve inflamasyon görülür. Hastalığın akut safhası geçtikten sonra supragingival ve subgingival temizlik, kök düzeltmesi ve polisaj yapılmalı, çürük lezyonları konservatif olarak tedavi edilmelidir. 4 hafta sonunda cerrahi olmayan periodontal tedavi ile etkilenen alanda iyileşme gözlenir [17].

\section{Akut Alerjik Gingivitis}

Organizmaya giren bir antijenin, immun cevap yerine bazı doku zedelenmeleri, enflamatuar reaksiyon ve hastalıkların ortaya çıkması şeklinde, abartılmış ve organizmaya zarar verici nitelikte oluşturduğu reaksiyonlara "aşırı duyarlılık" veya "alerji" denir. Alerji antijenle ilk temastan sonra değil, genellikle ikinci veya daha sonraki karşılaşmalarda meydana gelir [18].

Akut alerjik durumlarda dişetinin renginde belirgin değişiklikler olmaktadır. Bu renk değişimi parlak kırmızı renkten mor tonuna kadar değişebilir. Eritem, ödem, hiperplazi ve ülserlere rastlanabilir. Alerjik reaksiyonun hafiflemeye başlaması ile belirtiler de ortadan kaybolur. Alerjik reaksiyonlara diş macunları, dudak boyaları, protezlerin içerisindeki metil metakrilat komponentler, barbitüratlar, sülfonamidler, dilantin, penisilin gibi ilaçlar neden olabilir. Nikel alerjilerine de rastlanabilir [19].

\section{Dental Restoratif Materyaller}

Tip 4 alerji (kontakt alerjisi), alerjenle temastan 12-48 saat sonra klinik olarak görülür. Civa, nikel, altın, çinko, krom, palladyum ve akriliklerin alerjiye neden olduğu bilinmektedir. Alerjik reaksiyonlar oral liken planus ve lökoplaki lezyonlarına benzer. Lezyonlar kırmızımsı veya beyazımsıdır., bazen ülsere olabilirler. Neden ortadan kaldırılınca, lezyonlar geçer [20].

\section{Diş Macunu, Ağız Gargaraları, Sakızlar}

Nadir olarak alerji yaptıkları rapor edilmiştir. Alerjik reaksiyonların sebebi, macun ve gargaraların içeriklerindeki tatlandırıcılar ve koruyuculardır. Alerjik sahaların karakteristik özelliği, ateş kırmızısı ve ödematöz yapıda olmalarıdır. Bazen ülserasyonlar ve beyaz sahalar da oluşabilir. Dişetinden başka dudak, yanak ve dil mukozasında da benzer etkilenmeler görülebilir, cheilitis de tabloya eklenebilir. Alerjenin kullanımı bırakıldıktan sonra klinik görüntü geçer [20].

\section{Yiyecekler}

Gıdalar tip 1 ve tip 4 alerjik reaksiyonlara neden olabilir. Oral mukoza alerjisi olan hastaların \%20'den fazlasının kivi, şeftali, elma, kestane ve salama karşı aşırı duyarlııklı olabileceği bildirilmiştir. Bu yiyecekler yendikten sonra oral mukozada şiddetli şişmeler meydana gelebilir. Kırmızı biberin de gingivitis, gingivostomatitis veya plazma hücreli gingivitise neden olduğu bilinmektedir. Tanıyı koymak zordur [20]. En sık labial ve bukkal mukoza ve dilin laterali etkilenir. Ağız tabanı ve gingiva da etkilenebilir. Alerjenin kullanımı kesilince lezyonlar 1 hafta içinde kaybolur [18].

\section{Lateks Alerjisi}

Latex alerjisinin bulguları subklinik seyirden ağır sistemik reaksiyona kadar değişebilir. Mukozal temas, deri temasına göre daha şiddetli reaksiyonlara neden olabilir. Lateks içeren dental ürünler; amalgam taşıyıcıları, matriks bantları ve matriksler, anestezik karpüller, enjektörler, damlalıklar, endodontik dolgu materyalleri, ölçü materyalleri, bol, maskeler/ yüz koruyucuları, eldivenler, ortodontik lastik bantlar ve elastikler, ısırma plağı, polisaj diskleri, rubber dam, sakşın başlığıdır [18,21].

\section{Metal Zehirlenmeleri}

Metal zehirlenmesi görülen hastalarda dişetinin kanamalı, kızarık ve yer yer ülsere olduğu bildirilmiştir. Çeşitli metal zehirlenmelerinde dişetinde; arsenik koyu kırmızı, bizmut mavi-siyah, bakır mavi-yeşil, gümüş gri, kurşun mavi-siyah bant şeklinde değişikliklere neden olmaktadır [20].

\section{Akut Kandidiyazis}

Kandidiyazis, oral mukozanın en yaygın mikotik enfeksiyonudur. Candida Albicans gibi yüzeyel bir fungusun normale göre fazla büyümesinden kaynaklanır. Klinik olarak diffüz, kabarık veya yumuşak kadifemsi kıvamda, uzaklaştırılabilen beyaz mukozal plaklar şeklinde görülür [8].

Kandida enfeksiyonları için predispozan faktörler: çocukluk çağındaki immünolojik eksiklikler, endokrin bozukluklar (diabetes mellitus,hipoparatiroidizm, gebelik, sistemik steroid tedavisi), topikal kortikosteroid tedavisi, kserostomi, kötü ağız hijyeni, ilerlemiş malignite, malabzorpsiyon ve malnutrisyon, sistemik antibiyotik tedavisi, kanser kemoterapisi ve radyasyon tedavisi, AIDS'tir [22].

Axell ve diğerleri [23] tarafından revize edilen Candida sınıflaması şu şekildedir:

1. Primer Oral Kandidiyazis (akut formlar, kronik formlar, kandida ilişkili lezyonlar, kandidayla süperinfekte olmuş keratinize primer lezyonlar)

2. Sekonder Oral Kandidiyazis (oral bölgede görülen sistemik mukokutanöz kandidiyazis)

\section{Akut Pseudomembranöz Kandidiyazis}

Bu form, bağışıklığı baskılanmış kişilerde en yaygın olarak ortaya çıkan formdur. Özellikle infantlarda (yeni doğanlarda) görülür. Doğum esnasında annenin vajinal kanalından bulaşma 
ile oluşabilir. Bu tabloya "pamukçuk" ismi de verilebilir. Pamukçuk plakları dilde, palatinada ve bukkal mukozada süt artıkları ile karışabilen beyazımsı-krem renkte plaklardır. Kazınmaları sonrası yerlerinde kırmızı enflamasyonlu, parlak kanamalı ve eritematöz bir zemin açığa çıkar. Plaklar; nekrotik materyal, deskuame epitel hücreleri, fibrin, maya hücreleri ve hif, yiyecek artıkları ve bakterilerden oluşur. Ciddi olgularda hastalarda yanma, hassasiyet ve yutma güçlüğü gözlenir. Akut pseudomembranöz kandidiyazis yetişkinlerde kaşeksi, uzun süreli antibiyotik kullanımı, immünosüpresyon ve kontrol altında olmayan diyabet gibi nedenlere bağlı olarak gelişebilir [24].

\section{Akut Eritematöz Kandidiyazis}

Bu tip kandidiyazis, önceleri "Antibiyotik yaralı ağız" olarak bilinen, geniş spektrumlu antibiyotiklerin uzun süreli kullanımı sonucu meydana gelen formdur. Sıklıkla dilin dorsumunda ve palatinada lokalize eritematöz alanlarla karakterizedir. Bukkal mukozada daha az sıklıkta rastlanır. Eritematöz kandidiyazis, oral kandidiyazisin sürekli olarak ağrıyan tek formudur. Bu form bazen "atrofik kandidiyazis" olarak da tanımlanır [24].

Hafif lokalize oral kandidiyazis tedavisi genellikle topikal antifungallerle yapılır. Nistatin, ilaç seçiminde ilk tercihtir. Nistatinin oral süspansiyonu (100.000 IU/ml) gargara olarak 2 dakika boyunca günde 4 kez kullanılır ve sonrasında yutulur. Hastalar nistatinin oral süspansiyonunu kullandıktan sonra 20 dakika boyunca yeme içmeden kaçınmalıdır. Tedavi süresince ağız içi protezler kullanılmamalıdır. Tedavinin etkinliğinin değerlendirilmesi için bir sonraki randevu, antifungal tedavinin başlangıcından 3 ila 7 gün sonrasına verilir. Tedavi süresi 7-14 gün arasında değişiklik gösterir. Son klinik bulguların görülüp lezyonların iyileşmesinden sonra 2-3 gün daha antifungal tedaviye devam edilmesi önerilmektedir. Bunun nedeni bazı yazarların $[25,26]$ kandida seviyelerinin normal seviyeye ulaşmasının bu şekilde mümkün olduğunu önermesidir. Yüksek sakkaroz içeriği nedeniyle diabetus mellituslu hastaların tedavisinde kontrendikedir. Bu gibi durumlarda flukonazol $(5 \mathrm{mg} / \mathrm{ml})$ oral süspansiyon bir tedavi seçeneği olarak kabul edilebilir [24]. Daha dirençli kandida enfeksiyonlarının tedavisinde kullanılan flukonazol preparatları gastrointestinal kanaldan iyi abzorbe olur ve plazma yarılanma ömrü 25-30 saattir [27].

Klorheksidin glukonat, triklosan ve uçucu yağların da içinde bulunduğu çeşitli ağız gargaraları, antikandidal aktivite gösterir. Klorheksidin glukonat ile kombinasyon halinde kullanılan nistatinin etkinliğinin azaldığı yönünde raporlar vardır. Bu yüzden klorheksidin gargara kullanımından sonra nistatin tedavisi için 30 dakikalık bekleme süresi tavsiye edilir [28-30].

\section{Gingival Apse}

Gingival apse; mikrobiyal plak infeksiyonu, travma, yabancı cisim impaksiyonu gibi çeşitli nedenlerle ortaya çıkan lokalize, akut inflamatuar lezyondur. Klinik olarak kırmızı, pürüzsüz ve yumuşak kıvamlıdır. Bazen ağrılıdır. Sıklıkla fluktan bir şişlik gözlenir. Apseye komşu bölgelerdeki dişlerde perküsyon hassasiyeti vardır. Tedavi edilmeyen dişeti apsesi perfore olarak drene olur. Lezyon 24-48 saat içerisinde fluktan olur, baskı ile sarımsı bir iltihabi sıvı boşalması olabilir. Dişeti apsesinden iltihabi sıvı boşalınca harap olan saha granülasyon dokusuyla dolar ve bu doku zamanla organize olur [31].

Gingival apse tedavisinde öncelikle akut fazın atlatılması amaçlanır, daha sonra apseye neden olan problemin hemen uzaklaştırılması gerekir. Hastayı rahatlatmak için topikal veya lokal anestezikler uygulanır. Eğer mümkünse diştaşı temizliği ve kök düzleştirmesi yapılır [31]. Tedavide drenajı sağlamak için insizyon yapılır. Dişeti kenarının şeklinin bozulmasına ve dişeti çekilmesine yol açmamak için insizyon horizontal yapılmalıdır [32]. Kanama durduktan sonra, hastaya her gün 2 saatte bir ılık tuzlu suyla çalkalama yapması gerektiği hatırlatılıp hasta gönderilir. 24 saat sonra bölge yeniden değerlendirilir. Eğer apse periodontal dokulara kadar ilerlememişse, infeksiyonu elimine etmek için antibiyotik tedavisi genellikle yeterli olur. Fakat apse periodontal dokuları etkilemişse dişeti cebinden itibaren derin temizlik (küretaj) yapılmalıdır. Eğer çok fazla kemik kaybı ve ataçman kaybı varsa dişin ekstraksiyonu gerekebilir [31].

\section{Periodontal Apse}

Periodontal apse, dişin destek yapılarının hızla yıkılmasına yol açan akut bir lezyondur.

Periodontal apsenin 2 klinik tipi mevcuttur [33]:

Periodontitise Bağlı Periodontal Apse

Periodontitise bağlı periodontal apsenin enfeksiyonu 3 farklı aşamada oluşabilir [34]:

1. Tedavi edilmemiş periodontitis vakalarında

2. Periodontal tedavi esnasında

3. Periodontal bakım esnasında

\section{Periodontitise Bağlı Olmayan Periodontal Apse}

Periodontal apseler, ortodontik lastik, diş ipi gibi yabancı maddelerin impaksiyonu, endodontik aletle diş duvarının perforasyonu, lateral kist enfeksiyonu ve kökün enfeksiyonunu etkileyen lokal sebeplere bağlı olarak gelişebilir [34].

Periodontal apselerin klinik olarak pulpal apselerle ayırıcı tanısının yapılabilmesi gerekir. Periodontal apseler var olan bir periodontal ceple ilişkilidir, pulpa vitaldir, şişlik genellikle gin- 
gival dokuları ilgilendirir ve nadiren fistül görülür, ağrı küntdonuk ve lokalizedir, perküsyonda hassasiyet olabilir ya da olmayabilir [35].

Periodontal apsenin tedavisi için mevcut tedavi seçenekleri [34]:

1. Cep yoluyla drenaj veya insizyon

2. Diştaşı temizliği veya kök düzeltmesi

3. Periodontal cerrahi

4. Sistemik antibiyotikler

5. Diş çekimi

Periodontal enfeksiyonlardaki antibiyotik seçenekleri [35]:

Amoksisilin: 1 gram yükleme dozu, daha sonra 500mg, 3x1, 3 gün Klindamisin: 600 mg yükleme dozu, daha sonra 300mg, 4x1, 3 gün Azitromisin veya Klaritromisin= 1 gram yükleme dozu, daha sonra 500mg, 4x1, 3 gün

\section{Perikoronitis}

Perikoronitis, erüpsiyonu tamamlanmamış bir dişin kronunu çevreleyen gingivanın inflamasyonudur. Çoğunlukla mandibular 3. molar bölgesinde meydana gelir. Akut, subakut ya da kronik formlarda bulunabilir [1].

Klinik tabloda belirgin kırmızı, hacmi artmış, süpürasyonlu ve son derece hassas bir dişeti vardır. Kulak, boğaz ve ağız tabanına yansıyan ağrı mevcuttur. Hasta; ağrı, kötü tat ve ağzını kapatamaması nedeniyle rahatsızdır. İlgili bölgede yanakta şişlik ve lenfodenopatiye de sıklıkla rastlanır. Hastada ayrıca ateş, lökositoz ve halsizlik gibi sistemik bulgular vardır [1].

Perikoronitis tedavisi iltihabın şiddetine, sistemik komplikasyonların varlığına ve ilgili dişin ağızda kalma gerekliliğine göre yapılır. Şikayeti olmayan hastalarda bile ileride akut tablo gelişmesi riski nedeniyle perikoronitis tedavi edilmelidir. Tedavi aşamaları [2]:

1. Yiyecek birikintilerinin ve eksudanın temizlenebilmesi için bölgenin ılık suyla yıkanması

2. Flebin kaldırılarak bölgenin antiseptikle temizlenmesi, alttaki eklentilerin de temizlenerek ılık suyla yıkanması

Şiddetli vakalarda hastaya antibiyotik önerilir. Eğer flep boyutu artmışsa ve fluktan ise anteroposterior insizyon ile drenaj sağlanır. Akut semptomlar elimine edildikten sonra dişin ağızda kalıp kalmayacağına karar verilir. Dişin ağızda kalacaksa, perikoronal flep periodontal cerrahi ile elimine edilir. Doku elimine edildikten sonra bölgeye periodontal pat uygulanır ve 1 hafta sonra alınır. Perikoronal flepler ANUG için "primer inkübasyon zonları" olarak bilinir ve bunların eliminasyonu, hastalığın tekrar etmemesi için alınan önemli önlemlerden biridir [2].

\section{Maddi Destek ve Çıkar İlişkisi}

Çalışmayı maddi olarak destekleyen kişi/kuruluş yoktur ve yazarların herhangi bir çıkar dayalı ilişkisi yoktur.

\section{Kaynaklar}

1. Klokkevold P. R, Caranza F. A. Acute Gingival Infections. In Newman, M. G., Takei, H. H., Klokkevold, P. R., Caranza, F. A. (Eds.), Caranza's Clinical Periodontology. (Twelfth Edition). Canada. Elsevier Inc. 2015; 244-51.

2. Klokkevold PR, Caranza FA. Treatment of Acute Gingival Disease. In Newman, M. G., Takei, H. H., Klokkevold, P. R., Caranza, F. A. (Eds.), Caranza's Clinical Periodontology. (Twelfth Edition). Canada. Elsevier Inc. 2015; 460-64.

3. Amir J, Harel L, Smetana Z, Varsano I. Treatment of herpes simplex gingivostomatitis with aciclovir in children: a randomised double blind placebo controlled study. BMJ 1997; 314: 1800-1803.

4. Johnson BD, Engel D. Acute necrotizing ulcerative gingivitis. A review of diagnosis, etiology and treatment. Journal of Periodontology 1986; 57: 141-50.

5. Dennison DK, Smith B, Newland JR. Immune resposiveness and ANUG. Journal of Dental Research 1985; 64:197.

6. Horning GM, Cohen ME. Necrotizing ulcerative gingivitis, periodontitis, and stomatitis: clinical staging and predisposing factors. Journal of Periodontology 1995; 66: 990-98.

7. Barnes G. P, Bowles W.F, Carter H.G. Acute necrotizing ulcerative gingivitis: a survey of 218 cases. Journal of Periodontology 1973; 44: 35-42.

8. Oh T. J, Eber R, Wang, H. L. Periodontal diseases in the child and adolescent. Journal of Clinical Periodontology 2002; 29: 400-10.

9. Scully C, Felix D. H. Oral medicine--update for the dental practitioner. Aphthous and other common ulcers. British Dental Journal 2005; 199: 259-64.

10. Al-Omiri MK, Alhijawi M, AlZarea BK, Abul Hassan R.S, Lynch, E. Ozone treatment of recurrent aphthous stomatitis: a double blinded study. Scientific Reports 2016; 6: 27772.

11. Volkov I, Rudoy I, Freud T, Sardal G, Naimer S, Peleg R, Press, Y. Effectiveness of vitamin B12 in treating recurrent aphthous stomatitis: a randomized, double-blind, placebo-controlled trial. Journal of the American Board of Family Medicine 2009; 22: 9-16.

12. Gursoy MH, Altan MK, Noyan U, Kadir T, Cologlu S, Yilmaz, S. Evaluation of the effectiveness of Er:YAG laser and conventional periodontal treatment in a patient with acute streptococcal gingivitis: a 2-year follow-up. Photomedicine and Laser Surgery 2010; 28: 841-45.

13. Sukchotiratana M, Linton AH, Fletcher JP. Antibiotics and the oral streptococci of man. Journal of Applied Bacteriology 1975; 38: 277-94 
14. Dahlen G. Microbiology and treatment of dental abscesses and periodontal-endodontic lesions. Periodontology 2002; 28: 206-39.

15. Kennedy HF, Morrison D, Tomlinson D, Gibson BE, Bagg J, Gemmell CG. Gingivitis and toothbrushes: potential roles in viridans streptococcal bacteraemia. Journal of Infection 2003; 46: 67-70.

16. Gates RL, Cocke WM, Rushton TC. Invasive streptococcal infection of the periorbita and forehead. Annals of Plastic Surgery 2001; 47(5): 565-567.

17. Dilsiz A, Sevinc S. Therapy of a patient with acute streptococcal gingivitis: Case Report and Review of Literature. JSM Dentistry 2014; 2: 1025-28.

18. Oztas N, Tufekcioglu D. Diş hekimliği ve alerji. Cumhuriyet Üniversitesi Diş Hekimliği Fakültesi Dergisi 2003; 6: 37-42.

19. Holmstrup, P. Non-plaque-induced gingival lesions. Annals of Periodontology 1999; 4: 20-31.

20. Armitage GC. Periodontal diagnoses and classification of periodontal diseases. Periodontology 2000, 2004; 34: 9-21.

21. Nettis E, Colanardi MC, Ferrannini A, Tursi A. Reported latex allergy in dental patients. Oral Surgery, Oral Medicine, Oral Pathology, Oral Radiology and Endodontics 2002; 93: 144-48.

22. Ak G, Unur M, Guc U. Oral kandidiyazis. Atatürk Üniversitesi Diş Hekimliği Fakültesi Dergisi 1998; 8: 50-53.

23. Axell T, Samaranayake LP, Reichart PA, Olsen I. A proposal for reclassification of oral candidosis. Oral Surgery, Oral Medicine, Oral Pathology, Oral Radiology and Endodontics 1997; 84: 111-12.

24. Tarcın BG. Oral candidosis: Aetiology, clinical manifestations, diagnosis and management. Marmara University Faculty of Dentistry 2011; 1: 140-48.
25. Sherman RG, Prusinski L, Ravenel MC, Joralmon RA. Oral candidosis. Quintessence International 2002; 33: 521-32.

26. Zegarelli DJ. Fungal infections of the oral cavity. Otolaryngologic Clinics of North America 1993; 26: 1069-89.

27. Cirelli A, Rossi F, Ciardi M. Treatment of oropharyngeal and esophageal candidiasis with a new antifungal agent fluconazole in HIV-infected patients. . Current Therapeutic Research 1990; 47: 81-87.

28. Akpan A, Morgan R. Oral candidiasis. Postgraduate Medical Journal 2002; 78: 455-59.

29. Jeganathan S, Lin CC. Denture stomatitis--a review of the aetiology, diagnosis and management. Australian Dental Journal 1992; 37: 107-14.

30. Williams DW, Kuriyama T, Silva S, Malic S, Lewis MA. Candida biofilms and oral candidosis: treatment and prevention. Periodontology 2000, 2011; 55: 250-65.

31. Melnick PR, Takei HH. Treatment of Periodontal Abscess. In Newman, M. G., Takei, H. H., Klokkevold, P. R., Caranza, F. A. (Eds.), Caranza's Clinical Periodontology. (Twelfth Edition). Canada. Elsevier Inc. 2015; 465-69.

32. Herrera D, Roldan S, Gonzalez I, Sanz M. The periodontal abscess (I). Clinical and microbiological findings. Journal of Clinical Periodontology 2000; 27: 387-94.

33. Herrera D, Roldan S, Sanz M. The periodontal abscess: a review. Journal of Clinical Periodontology 2000; 27: 377-86.

34. Corbet EF. Diagnosis of acute periodontal lesions. Periodontology 2000, 2004; 34: 204-16.

35. Parameter on acute periodontal diseases. Journal of Periodontology 2000; 71: 863-66. 